\title{
Six Years Follow-up of Diphenylthiourea Treatment
}

\author{
A. R. D A V IS ON, M.R.G.s. (Eng.), L.R.G.P. (Lond.) \\ Westfort Institution, Pretoria, South Africa.
}

In 1957 lepromatous patients were selected for a trial of diphenylthiourea (DPT or Ciba I 9o6) and its effects were compared with the results obtained with diamino-diphenyl-sulphone (DDS). The results were analysed at the end of two years when the project was stopped and all cases were placed on DDS. The subsequent history of the cases were investigated after six years (i.e. in 1963). The results after two years and six years are here reported.

METHOD

We selected 30 lepromatous patients and formed 3 equal groups, taking into account ( $\mathrm{I}$ ) bacillary index, (2) degree of lepromatous involvement, (3) history of erythema nodosum leprosum (ENL), (4) sex, and (5) weight.

Patients in group A received DDS only.

Patients in group B received DPT only.

Patients in group C received both DDS and DPT.

\section{Dosage}

The dose of DDS was 200 mgm once daily for 6 days per week. (In I 959 the maximum dose of DDS was reduced to I oo mgm. daily).

The dose of DPT was 50 mgm per kilo of body weight given in one dose. The tablets contained $500 \mathrm{mgm}$ so the dosage varied from 5 to 8 tablets daily.
The patient on combined treatment received full doses of each drug.

\section{Examinations}

(I) Clinical: every two months.

(2) Skin smears: every two months from 4 sites.

(3) Haemoglobin estimations : every two months.

(4) Reactions: daily observation when reactions occurred.

\section{Dropped from Project}

Group A One patient died.

Group B One patient died, one developed pulmonary tuberculosis and one absconded.

Group C One patient died, one transferred within the first two years and one died in the $4^{\text {th }}$ year.

\section{Results after second year}

Patients are photographed at the beginning and end of each project and this is of help in assessing the changes in a patient. Patients are then assessed as e.g. improved, markedly improved, stationary or worse. In an attempt to make the changes statistically clearer we use what we call a 'Lesion Index'. In this the infiltrations, the maculae or plaques, and the nodules or papules are graded according to severity, from o to 3 in three sites, i.e. in the face, trunk and limbs. The maximum severity for one patient would then be 9 .

The results after two years were:

T A B L E

Lesion Indices after two years of treatment

\begin{tabular}{|c|c|c|c|c|c|c|c|c|c|}
\hline \multirow[t]{2}{*}{ Group } & \multirow{2}{*}{$\begin{array}{l}\text { Number of } \\
\text { Cases Remaining } \\
\text { in Project }\end{array}$} & \multicolumn{2}{|c|}{$\begin{array}{l}\text { Infiltration } \\
\text { Index }\end{array}$} & \multicolumn{2}{|c|}{$\begin{array}{l}\text { Macules or } \\
\text { Plaques Index }\end{array}$} & \multicolumn{2}{|c|}{$\begin{array}{c}\text { Nodule or } \\
\text { Papule Index }\end{array}$} & \multicolumn{2}{|c|}{ Total Lesion Index } \\
\hline & & Before & After & Before & After & Before & After & Before & After \\
\hline A. DDS only & 9 & 36 & 20 & 9 & o & 6 & 4 & $5^{1}$ & 24 \\
\hline B. DPT only & 7 & 30 & 14 & 9 & I & o & o & 39 & I 5 \\
\hline $\begin{array}{l}\text { C. DDS and } \\
\text { DPT }\end{array}$ & 8 & 31 & 23 & 8 & 5 & 3 & 2 & 42 & 30 \\
\hline
\end{tabular}


From this it is obvious that DDS alone and also DPT alone have a definite effect on the clinical lesions. It also seems that combining DPT with DDS is not so good as either DDS or DPT alone.

\section{Reactions}

Reactions in the form of erythema nodosum leprosum, or neuritis or acute swelling of lesions occurred in all groups. However, they were much less in the group which received no DDS i.e. Group B.

\section{Bacteriology}

As there is a monthly fluctuation in the bacteriological index of all groups (and this applies to all our investigation projects) we took the bacterial smears for two months at the beginning and two months at the end of the second year. The results were:

Group A. (9 cases) Bacterial Index dropped from I 7.2 to Io.

Group B. (7 cases) from I6.7 to I o.

Group C. (8 cases) from i 6.6 to $9 \cdot 7$.

It may be inferred from this that DPT has the same suppressive effect on bacilli as DDS or the combined DDS and DPT.

\section{Results after six years}

Patients who died, absconded, developed tuberculosis or were transferred were excluded from the final analysis. It was found that all remaining patients had become negative. One patient had died in the $4^{\text {th }}$ year. The periods required to achieve negativity were:

Group A. (9 patients) averaged 5 years.

Group B. ( 7 patients) averaged 5 years, 2 months. Group C. (7 patients) averaged 5 years.

The significance of this finding is that patients who were deprived of DDS for two years were not delayed in their healing.

\section{CONGLUSIONS}

DPT in its clinical effect and its effect on bacilli is as efficacious as DDS. However, it has to be given at the rate of 4 or more tablets per day as opposed to the one tablet of DDS. Also, tablet for tablet, it is I o times the price of DDS, so the treatment costs at least 40 times as much.

We therefore do not consider it as a substitute for DDS and only give it under certain indications.

I N D I C A T I O N S

( I) DPT may be substituted for DDS where the patient has repeated reactions under DDS. We are not satisfied that this is of much avail.

(2) DPT may be substituted for DDS when the patient's response to DDS is slow. We have no figures to confirm that this is of use.

(3) DPT is definitely indicated when the patient shows any type of psychosis under DDS.

A G KN OWLEDGEMENTS

I am obliged to the Secretary for Health for authority to publish these notes. 